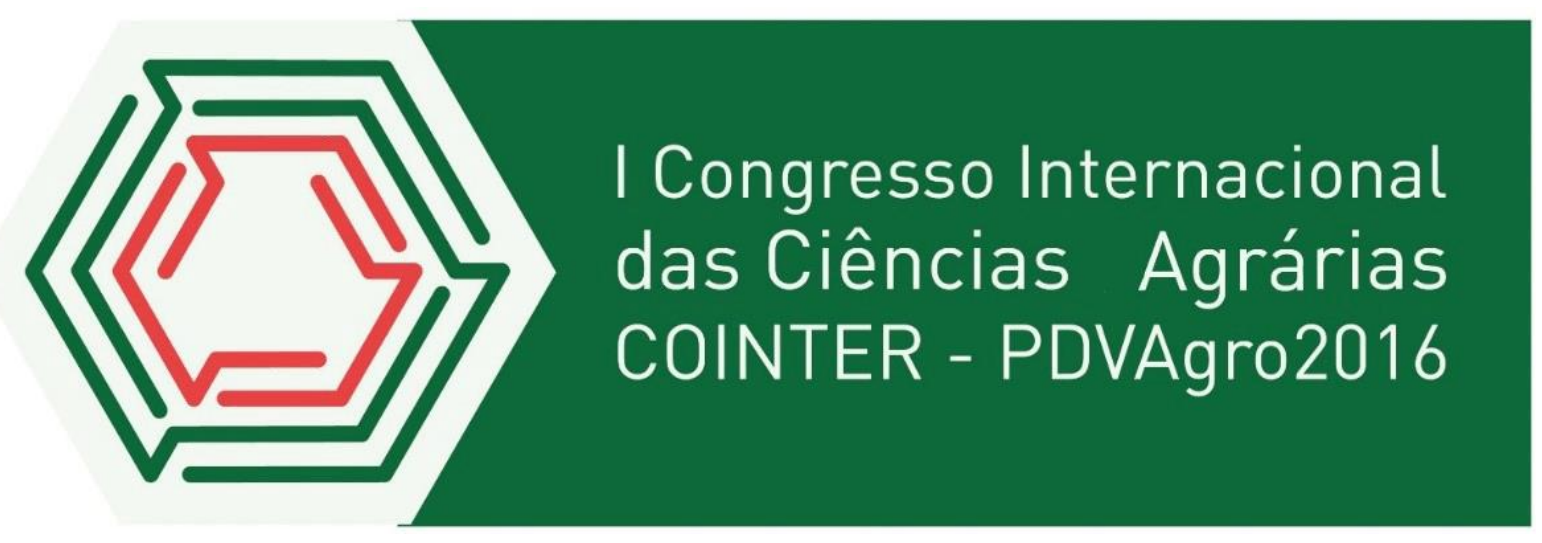

\title{
ANÁLISE DO COMPORTAMENTO DOS PREÇOS PAGOS AOS PRODUTORES DE LEITE DO BRASIL E A FORMAÇÃO DO PREÇO NA BAHIA
}

\author{
Apresentação: Comunicação Oral
} Autor Josefa Edileide Santos Ramos ${ }^{1}$; Marcelo da Costa Borba ${ }^{2}$; Ana Paula Santana de Melo ${ }^{3}$
André de Souza Melo Leonardo Ferraz Xavier ${ }^{4}$

\section{Resumo}

Este estudo teve como objetivo analisar o comportamento dos preços pagos aos produtores de leite entre as principais bacias brasileira, buscando inferir se há algum estado que afete a formação do preço do leite na Bahia, no período de janeiro de 2000 a junho de 2015. Para este estudo foi utilizado o método de Vetores Auto Regressivos, a análise das séries foi realizada utilizando o Teste de Causalidade de Granger e o Analise de variância. Os resultados evidenciaram que o estado de Minas Gerais lidera a formação de preços nos demais estados, além desta influência os estados são influenciados pelos seus próprios preços. No entanto a Bahia apresentou maior influência em seus preços que os demais estados, este fato pode ser explicado em decorrência da valorização das políticas de preço ao produto no Nordeste ocasionados pelos períodos de estiagem. Evidenciou-se a importância de Minas Gerais na formação de preços na Bahia, devido, principalmente, à condição de maior produtor de leite do país e pelo elevado investimento em tecnologia e o grande número de indústrias instaladas de transformação da matéria-prima leite. Pode-se observar a relação de integração entre os mercados produtores de leite, assim como a transmissão de preços intermercados. $\mathrm{O}$ fato de observar que os mercados dos estados selecionados são integrados permite concluir que eventuais políticas que afetam o processo de formação de preços em um estado vão também ter efeito nos preços de todos os demais estados com os quais ele esteja integrado, especialmente naqueles nos quais as relações são fortes.

Palavras-Chave: Bacia leiteira. Transmissão de preços. Vetores Auto Regressivos

\section{Introdução}

O potencial de produção existente e o mercado de lácteos em plena expansão são fatores que evidenciam as boas oportunidades de negócios envolvendo a pecuária de leite no Brasil. O país vem apresentando contínuo crescimento na produção, a importância no

\footnotetext{
1 Pós-Graduação em Administração e Desenvolvimento Rural, UFRPE, edileideramos@gmail.com

2 Pós-Graduação em Administração e Desenvolvimento Rural, UFRPE, marcelodcborba@gmail.com

3 Pós-Graduação em Administração e Desenvolvimento Rural, UFRPE, paulasantanademelo@gmail.com

4 Doutorado em Economia, UFPE, andredesouzam@gmail.com

$5 \quad$ Doutorado em economia, UFPE, leonardoferraz@gmail.com
} 
desempenho econômico no país é incontestável. Em 2014, a produção de leite foi de 35,17 bilhões de litros, representando um aumento de 2,7\% em relação à registrada no ano anterior (IBGE, 2014a).

Atualmente o país se encontra entre os maiores produtores de leite de vaca do mundo, de acordo com o Departamento de Agricultura dos Estados Unidos (United States Department of Agriculture - USDA), o Brasil ocupou a quinta posição no ranking mundial de produção de leite em 2014, atrás da União Europeia, Índia, Estados Unidos e China (IBGE, 2014b). A grande disponibilidade de fatores de produção favorece a expansão desse segmento da economia. A expansão do setor se configura como um importante instrumento de desenvolvimento regional na medida em que gera emprego e renda nas áreas com vocação para o desenvolvimento de suas atividades.

Neste contexto, o processo de planejamento da atividade torna-se fundamental para a consolidação de qualquer expansão. No entanto o planejamento por parte dos produtores é dificultado pelas oscilações no preço do produto. Isso porque a atividade está sujeita a diversos eventos, como os fatores socioeconômicos, tecnológicos, culturais e edafoclimáticas, que, ao afetarem as condições de oferta, alterariam também os seus preços.

Assim, a geração de informações que auxiliem no entendimento do comportamento dos preços é essencial para a expansão dos negócios. Desta forma, os produtores com base em melhores informações poderiam se planejar melhor e dispor de informações relevante no processo decisório. Desta forma, as informações sobre transmissão de preços podem se tornar um subsidio no processo de tomada de decisões pelos agentes de mercado, uma vez que garantem um grande conhecimento sobre o mercado no qual estão atuando (DIAS et al., 2007).

A análise da transmissão de preços dos agentes que envolvem as cadeias produtivas fornece informações importantes a respeito das operações e funcionamento do mercado. $\mathrm{O}$ preço é um mecanismo que acaba promovendo a união de vários mercados, sendo que sua dinâmica permite obter informações de grande relevância, permitindo compreender como o mercado está (GOODWIN; HARPER, 2000).

Diante deste contexto, este estudo tem como objetivo analisar o comportamento dos preços históricos do leite pagos aos produtores das principais bacias brasileira, observando se há uma relação estável de longo prazo entre as variáveis, buscando inferir se há algum estado que afete a formação do preço do leite na Bahia. Para realização dessa análise foram escolhidas as bacias de MG, PR, RS, GO, SP e BA, devido à representatividade desses estados na atividade leiteira. Espera-se que o trabalho possa contribuir, por meio da aplicação 
de testes empíricos na análise do processo de transmissão de preços ao longo da cadeia produtiva do leite no Estado da Bahia, já que existem poucos estudos que associam o processo de transmissão de preços com o mercado de leite.

\section{Fundamentação Teórica}

A produção de leite de vaca no Brasil cresceu a uma taxa relativamente constante desde 1991. O país saiu do patamar de 15,1 bilhões de litros de leite produzidos naquele ano, alcançando o de 35,17 bilhões de litros em 2014 (IBGE, 2014a). Isto devido às mudanças econômicas ocorridas desde a década de 1990. Essas mudanças estão associadas, principalmente, aos impactos da estabilização da economia em decorrência do Plano Real, desregulamentação do mercado e abertura econômica que exigem ajustamentos estratégicos e estruturais do setor (JANK; FARINA; GALAN, 1999).

O Brasil é tradicionalmente um país exportador de leite. Apesar de ocupar a quinta posição sua participação no mercado mundial, não é suficiente para atendar a demanda nacional (USDA, 2016). De acordo com Correr et al., (2015) o país tem melhorado seu desempenho no comércio internacional do produto. A produção primária do leite está presente em todo o território brasileiro, contudo destaca-se em algumas regiões. Como já observado os maiores produtores de leite do país concentram-se principalmente nas regiões Sul e Sudeste, conforme pode ser observado na Tabela 2 (IBGE, 2014b).

Tabela 1:Quantidade de leite produzida e variação relativa, segundo as Grandes Regiões

\begin{tabular}{|c|c|c|c|}
\hline \multirow{3}{*}{$\begin{array}{lrr}\text { Grandes } & \text { Regiões, } & \text { em } \\
\text { ordem decrescente } & \text { da } \\
\text { quantidade produzida. } & \end{array}$} & \multicolumn{3}{|c|}{ Produção de Leite } \\
\hline & \multicolumn{2}{|c|}{ Quantidade (1000 litros) } & \multirow{2}{*}{$\begin{array}{l}\text { Variação } \\
\text { Relativa (\%) }\end{array}$} \\
\hline & 2013 & 2014 & \\
\hline Brasil & 34.255 .236 & 35.174 .271 & 2,7 \\
\hline Sul & 11.774 .330 & 12.200 .824 & 3,6 \\
\hline Sudeste & 12.019 .946 & 12.169 .774 & 1,2 \\
\hline Centro-Oeste & 5.016 .291 & 4.969 .238 & $-0,9$ \\
\hline Nordeste & 3.598 .249 & 3.888 .285 & 8,1 \\
\hline Norte & 1.846 .419 & 1.946 .150 & 5,4 \\
\hline
\end{tabular}

Fonte: IBGE , (2014b)Produção Pecuária Municipal.

Em 2014, o Sul assumiu a primeira posição no ranking, com 34,7\% da produção nacional. A produção leiteira nacional é bastante concentrada nessas regiões. Os seis principais estados produtores (Minas Gerais, Rio Grande do Sul, Paraná, Goiás, Santa Catarina e São Paulo) correspondem a 76,8\% da produção total do país. E ainda, adicionando o volume produzido pela Bahia tem-se a participação $(80,3 \%)$ desses sete estados na produção nacional. 
O estado de Minas Gerais foi o principal produtor de leite em 2014, com 9,37 bilhões de litros, o que corresponde a $26,6 \%$ do total da produção nacional. Na segunda colocação está o estado do Rio Grande do Sul com 4,68 bilhões representando 13,3\%, seguido pelo Paraná com 4,53 bilhões correspondente a 12,9\% (IBGE, 2014b).

O estado de Minas Gerais apresenta posição de liderança na produção de leite em relação aos demais, isso porque, os produtores especializados que investem em tecnologia, economias de escala e diferenciação do produto se concentram em bacias leiteiras tradicionais como a do estado (CARVALHO et al., 2007). Minas Gerais possui tradição na produção leiteira e um grande rebanho de animais de genética apurada, além de boas condições climáticas e boa nutrição dos rebanhos leiteiros, o que se reverte no sucesso da produtividade leiteira.

O Brasil possui um grande diferencial produtivo entre as regiões. Se de um lado existe produtores tradicionais, por outro lado, estão os estados de pouca tradição na criação do gado leiteiro, aonde esta atividade tem pouca representatividade, como os estados do norte e nordeste. Estes possuem clima quente, o que dificulta a criação das raças leiteiras mais produtivas. Também existe uma deficiência natural nas pastagens devido as dificuldades climáticas e solos mais pobres que não permitem o cultivo de pastagens de qualidade superior, ou para a implantação destas, os custos são muito elevados. Devido a estes fatores que a atividade leiteira é distinta no território nacional, com várias particularidades e diferentes níveis tecnológicos entre as regiões (SEAB, 2014).

Observando as dificuldades impostas pelo ambiente econômico, cultural e edafoclimático em que os estados nordestinos estão inseridos, o estado da Bahia apresenta um maior destaque na produção de leite, apresentando como o maior produtor de leite do Nordeste com $31,2 \%$ da produção regional, isto se deve ao fato da sua localização privilegiada, que pode possibilitar o acesso a outros estados da região.

Em termos quantitativos, a produção da Bahia (1.212.091) está bem próxima da de São Paulo (1.776.563), o que pode ser um indicio de que, mantido o ritmo de crescimento que o estado apresenta, a Bahia venha a ser uma importante bacia leiteira brasileira (IBGE, 2014a). Regionalmente, o leite tem sido comercializado, a nível de fazenda, com preços entre $\mathrm{R} \$ 1,05$ e $\mathrm{R} \$ 1,20$. A abundância dos subprodutos do leite e do milho com preços competitivos, favorece a produção, além do uso de pastos irrigados durante o período de estiagem (SAMPAIO, 2014).

O setor produtor do leite foi marcado pela intervenção governamental até os anos 90, neste período a Comissão Internacional de Preços (CIP) controlava os preços dos produtos 
lácteos e definia aos produtores. Desta forma, a renda obtida pelo produtor estava protegida pelo regime de fixação de preço, mesmo com a oscilação que ocorria com a sazonalidade da produção (FERNANDES; BRAGA; LIMA, 2010).

Com a desregulamentação do setor, a abertura comercial e a estabilidade de preços formaram um novo cenário, em que o preço do leite passou a ser definido pela interação entre oferta e demanda. Como forma de analisar a oferta e a demanda, leva-se em consideração que o preço equilibra as quantidades produzidas e consumidas. Nesse sentido, os preços podem servir como um mecanismo eficiente de comunicação para regular tanto a quantidade demandada quanto a quantidade ofertada, alcançando o equilíbrio.

Porém, o fato de compartilharem informações de longo prazo semelhantes faz com que os preços de um mercado integrado sofram influências não somente das condições locais de oferta e demanda, como também das condições das demais localidades(CUNHA et al., 2011). Com relação a integração de mercados, esta consiste na interdependência de preços em diferentes regiões ao longo do tempo, compartilhando a mesma informação porem isto não depende que os mercados estejam diretamente ligados pelo comércio (FACKLER; GOODWIN, 2001). A relação espacial de preços na agricultura assume que a diferença de preços entre duas regiões será apenas igual aos custos de transação (FAMINOW; BENSON, 1990). Isto ocorre devido a arbitragem espacial em que o agente compra o bem em um local mais barato para revendê-lo em outra localidade mais caro, com o intuito de obter lucro(ROSADO, 2006).

Esta igualdade de preços é denominada Lei do Preço Único (LPU), a qual sugere que variações de preços no mercado externo de determinado produto são transmitidas para o mesmo produto, porém, no mercado doméstico. A lei do preço único pode ser causada esporadicamente pela arbitragem espacial ou quando a arbitragem e comercio ocorrem de forma continua. Para Fackler e Goodwin, (2001) a integração de mercado é uma medida de grau, em que choques de demanda e de oferta que surgem em uma região são transmitidos para outra região.

Assim, segundo Fontes, Silva e Lima, (2005) medir a integração espacial (movimentação de preços em diferentes locais, medida pela correlação entre os preços) de um mercado pode ser visto como um dado básico para o entendimento de como esse mercado funciona. Como também para formulação de políticas governamentais para o setor visando tornar o mercado mais eficiente, bem como para os agentes da cadeia produtiva, pois choques de preços em uma região podem ser transmitidos a outras, levando a incertezas a respeito dos preços e renda (NOGUEIRA, 2001). 
Alguns autores vêm estudando sobre a formação espacial de preços entre os estados produtores de leite no Brasil. Fernandes, Braga e Lima, (2010), verificaram a elasticidade na transmissão e a formação espacial de preços entre os principais estados produtores e constataram que Minas Gerais explicam grande proporção da variabilidade dos preços de leite ao produtor dos estados. Já o estado de São Paulo, apesar de representar o maior mercado consumidor de leite e derivados, apresentou uma taxa de crescimento negativa, pois vem perdendo participação na produção total de leite desde o ano de 1998, especialmente para os estados do Sul.

Loures, Alvim e Lima, (2013) identificaram que a influência de Minas Gerais sobre os preços do Rio Grande do Sul não é muito significativa. Esse fato pode ser justificado em função da maior concentração de indústrias transformadoras dessa matéria-prima no estado, contribuindo para que as produções sejam feitas local/regionalmente.

Carvalho et al., (2014) realizaram um estudo da intregação inter e intramercado o caso dos preços e derivados de leites no Brasil. Quanto à análise de preços inter mercados, os resultados indicam que o estado de Minas Gerais é o maior formador do preço do leite pago ao produtor, seguido pelo estado de São Paulo. Já os estados do Rio Grande do Sul e Paraná sofrem influência maior dos seus próprios preços, do que do estado de São Paulo, enquanto que o estado de Goiás ocupa a posição de tomador de preços.

Este cenário aponta para a necessidade de políticas de preços para o leite focalizadas nos estados de Minas Gerais e São Paulo. No caso de Minas Gerais isto se justifica por ser o maior produtor. Já São Paulo se destaca como maior mercado consumidor. Desta forma, os efeitos das políticas tendem a ser transmitidos para outros estados, dada a forte correlação de movimentos de mercados. Além disso, aqueles estados que vêm se destacando tanto na produção quanto na comercialização leiteira têm se destacado na liderança de preços, como é o caso de Goiás e dos estados do Sul (FERNANDES; BRAGA; LIMA, 2010).

\section{Metodologia}

Este trabalho caracteriza-se como uma pesquisa quantitativa de base econométrica. $\mathrm{O}$ modelo que a embasa trata-se da metodologia de Vetores Auto Regressivos (VAR). Os dados são de base secundaria e utiliza series temporais para análise. As series temporais é "um conjunto de observações dos valores que uma variável assume em diferentes momentos no tempo" (GUJARATI, 2006, p. 19).

Para analise foram utilizadas as séries temporais dos preços de leite pago aos pecuaristas rurais referentes aos estados de Minas Gerais, Paraná, Rio Grande do Sul, Goiás, 
São Paulo e Bahia de janeiro de 2000 a junho 2015. Os dados foram obtidos no Cepea (ESALQ/USP), totalizando 186 observações. O Cepea utilizou a taxa de cambio (em $\mathrm{R}$ \$/unidade de moeda estrangeira) para corrigir os preços. Devido à constante desvalorização da moeda nacional ( $\mathrm{R}$ ) em períodos de inflação, torna-se necessário corrigir os preços de produtos agropecuários em relação a um dado período. O programa utilizado para as análises foi o Regression Analysis of Time Series (RATS).

A análise das séries foi realizada utilizando o Teste de Causalidade de Granger e o VAR. Como os dados analisados tratam-se de series temporais, o primeiro teste a ser realizado é verificar se as séries são estacionárias em nível ou se tornam estacionárias nas diferenças. O primeiro passo da estimação é detectar a ordem de integração das variáveis de preço pago ao produtor para todos os estados analisados. Realizados os testes ADF de raiz unitária constatou-se que as séries de preços de leite pago ao produtor dos estados de MG, PR, RS, GO, SP e BA, não são estacionárias. Todavia, o mesmo teste, e com as mesmas condições, com a variável em primeira diferença reportou a estacionariedade para as séries, ou seja, ambas as séries são estacionárias ao nível de 5\% de significância.

O próximo passo consiste em determinar o número de defasagens utilizados no modelo VAR. Com relação a escolha do número de lags (defasagens), optou-se pela utilização dos critérios de informação de Akaike (AIC) e Schwartz (SBC). O resultado apontado pelo critério de AIC indicou duas defasagens para o modelo, enquanto os critérios SBC sugeriram a inclusão de apenas uma defasagem. Com relação a escolha do número de lags (defasagens) que devem ser incluídas no modelo VAR, optou-se pelos critérios de informação de Schwartz (SBC).

Após a determinação do número de defasagens pelo critério de Schwartz, partiu -se para a análise dos resíduos. Para tanto, é necessário ordenar as variáveis, partindo daquela menos endógena para a mais endógena. A ordenação das variáveis para a estimação do modelo de transmissão de preços intermercados foi: MG, RS, PR, GO, SP e BA, que, referem-se aos estados de Minas Gerais, Rio Grande do Sul, Paraná, Goiás, São Paulo e Bahia, respectivamente. Essa ordenação foi escolhida seguindo um ranking de estados produtores de leite, conforme já referenciado. Considerando a ordem crescente de produção.

Por último, aplica-se o teste de causalidade de Granger (1969), para determinar a existência ou não de um equilíbrio de longo prazo entre essas bacias leiteiras. Assim, estabelecer as relações causais entre os estados e a intensidade em que os preços são transferidos de um estado para outro. O estudo concentra-se na hipótese de que os preços 
recebidos pelos produtores de leite da Bahia estão sendo afetados pelos preços de outros estados.

\section{Resultados e Discussão}

A partir da estimação da modelagem VAR, torna-se possível a análise da decomposição histórica da variância do erro de previsão em relação às séries de preços em análise permite avaliar o poder explanatório de cada variável do modelo sobre as demais.

Estimado o modelo, partiu-se para a análise da decomposição da variância das series preço pagos ao produtor. A análise de decomposição de variância explica, em percentuais, a participação de cada variável na explicação das outras. A Tabela 2 apresenta a porcentagem da variância do erro de previsão decorrente de cada variável endógena ao longo do cenário de previsão.

Tabela 2: Decomposição da variância das series preço do leite pago ao produtor no período de janeiro de 2000 a junho 2015

\begin{tabular}{|c|c|c|c|c|c|c|c|}
\hline \multicolumn{8}{|c|}{ MG } \\
\hline Step & Std Error & MG & RS & PR & GO & SP & BA \\
\hline 1 & 0.02059807 & 100.000 & 0.000 & 0.000 & 0.000 & 0.000 & 0.000 \\
\hline 10 & 0.02893649 & 80.464 & 5.611 & 4.150 & 3.930 & 1.525 & 4.320 \\
\hline 20 & 0.02893653 & 80.464 & 5.611 & 4.150 & 3.930 & 1.525 & 4.320 \\
\hline 30 & 0.02893653 & 80.464 & 5.611 & 4.150 & 3.930 & 1.525 & 4.320 \\
\hline 40 & 0.02893653 & 80.464 & 5.611 & 4.150 & 3.930 & 1.525 & 4.320 \\
\hline \multicolumn{8}{|c|}{ RS } \\
\hline Step & Std Error & MG & $\mathrm{RS}$ & PR & $\mathrm{GO}$ & SP & $\mathrm{BA}$ \\
\hline 1 & 0.02288480 & 66.453 & 7.016 & 26.532 & 0.000 & 0.000 & 0.000 \\
\hline 10 & 0.02984320 & 63.192 & 11.680 & 16.489 & 2.593 & 0.906 & 5.140 \\
\hline 20 & 0.02984323 & 63.192 & 11.680 & 16.489 & 2.593 & 0.906 & 5.140 \\
\hline 30 & 0.02984323 & 63.192 & 11.680 & 16.489 & 2.593 & 0.906 & 5.140 \\
\hline 40 & 0.02984323 & 63.192 & 11.680 & 16.489 & 2.593 & 0.906 & 5.140 \\
\hline \multicolumn{8}{|c|}{$\mathrm{PR}$} \\
\hline Step & Std Error & MG & $\mathrm{RS}$ & PR & GO & SP & $\mathrm{BA}$ \\
\hline 1 & 0.02204234 & 66.043 & 33.957 & 0.000 & 0.000 & 0.000 & 0.000 \\
\hline 10 & 0.02674868 & 61.463 & 29.983 & 1.980 & 1.052 & 0.864 & 4.658 \\
\hline 20 & 0.02674870 & 61.463 & 29.983 & 1.980 & 1.052 & 0.864 & 4.658 \\
\hline 30 & 0.02674870 & 61.463 & 29.983 & 1.980 & 1.052 & 0.864 & 4.658 \\
\hline 40 & 0.02674870 & 61.463 & 29.983 & 1.980 & 1.052 & 0.864 & 4.658 \\
\hline \multicolumn{8}{|c|}{ GO } \\
\hline Step & Std Error & MG & RS & PR & GO & SP & BA \\
\hline 1 & 0.02346157 & 79.331 & 0.621 & 0.901 & 19.148 & 0.000 & 0.000 \\
\hline 10 & 0.03143310 & 70.175 & 4.776 & 3.873 & 14.102 & 1.234 & 5.840 \\
\hline 20 & 0.03143313 & 70.175 & 4.776 & 3.873 & 14.102 & 1.234 & 5.840 \\
\hline 30 & 0.03143313 & 70.175 & 4.776 & 3.873 & 14.102 & 1.234 & 5.840 \\
\hline 40 & 0.03143313 & 70.175 & 4.776 & 3.873 & 14.102 & 1.234 & 5.840 \\
\hline \multicolumn{8}{|c|}{ SP } \\
\hline Step & Std Error & MG & RS & PR & GO & SP & BA \\
\hline 1 & 0.02112521 & 79.600 & 5.416 & 0.343 & 0.343 & 14.298 & 0.000 \\
\hline 10 & 0.02885186 & 71.885 & 8.234 & 3.579 & 2.858 & 8.737 & 4.707 \\
\hline 20 & 0.02885190 & 71.885 & 8.234 & 3.579 & 2.858 & 8.737 & 4.707 \\
\hline 30 & 0.02885190 & 71.885 & 8.234 & 3.579 & 2.858 & 8.737 & 4.707 \\
\hline 40 & 0.02885190 & 71.885 & 8.234 & 3.579 & 2.858 & 8.737 & 4.707 \\
\hline \multicolumn{8}{|c|}{ B } \\
\hline
\end{tabular}




\begin{tabular}{l|c|c|c|c|c|c|c}
\hline Step & Std Error & MG & RS & PR & GO & SP & BA \\
\hline 1 & 0.01697722 & 51.142 & 0.740 & 0.518 & 0.575 & 0.222 & 46.804 \\
10 & 0.02127252 & 61.607 & 2.618 & 1.620 & 2.771 & 0.762 & 31.351 \\
20 & 0.02127252 & 61.607 & 2.618 & 1.620 & 2.771 & 0.762 & 31.351 \\
30 & 0.02128649 & 61.607 & 2.618 & 1.620 & 2.771 & 0.762 & 31.351 \\
40 & 0.02128711 & 61.607 & 2.618 & 1.620 & 2.771 & 0.762 & 31.351 \\
\hline
\end{tabular}

Fonte: Elaborado pelo autor (2015), com base nos dados da pesquisa

Constatou pelos resultados que Minas Gerais é o estado com maior poder explicativo sobre os preços de todos os estados. Os preços de Minas Gerais possuem ao final de 40 meses, poder explicativo de 80,46\% sobre si mesmo, $63,19 \%$ sobre os preços praticados no Rio Grande do Sul, 61,46\% dos preços do Paraná, 70,17\% sobre os preços Goiano, 71,88\% dos preços praticados em São Paulo e 61,6\% sobre a Bahia. Minas Gerias tem um papel importante na formação de preços dos demais estados este efeito ocorre devido ao fato do estado de Minas Gerais ser o maior produtor de leite do país, e investir em tecnologias de ponta. Desta forma, os preços praticados nos outros estados dependem, em grande parte, dos preços praticados em Minas Gerais.

Na observação dos dados referentes ao Rio Grande do Sul, no primeiro mês após um choque 7,11\% sobre si mesmo, 26,53\% do seu preço é explicado por choques no Paraná, porem ao longo do tempo ao final dos 40 meses o preço pago ao produtor neste estado é explicado em 11,68\% sobre si mesmo e 16,48\% pelo preço do Paraná. Já no Paraná, 29,98\% de seus preços são explicados por choques no Rio Grande do sul. Desta forma, para estes dois estados, o maior formador de preços é o estado de Minas Gerais, seguido pelos próprios preços, de forma que os preços praticados no Rio Grande do Sul dependem, em grande parte, dos preços praticados no Paraná reciprocamente.

No caso do preço pago ao produtor de Goiás, $14,10 \%$ da sua variância pode ser explicada pelos próprios preços, 5,84\% pelos preços baianos, 4,77\% pelos preços pagos ao produtor no Rio Grande do Sul, 3,87\% pelo Paraná e apenas 1,23\% pelo estado de são Paulo. Os produtores goianos sofrem com o processo de concorrência e seguem o estado com maior poder explicativo do mercado Minas gerais.

Avaliando o movimento dos preços do estado paulista, tem-se que $8,73 \%$ de sua variância é explicado pela variância na sua própria cotação, enquanto que a variância das cotações de Rio Grande do Sul, Bahia, Paraná e Goiás explicam 8,23\%, 4,7\%, 3,57\% e 2,85 da variância de seu preço, respectivamente. Portanto, o principal determinador dos preços pago ao produtor paulista é o estado de Minas Gerais. Sabe-se o estado é grande importador de leite, de modo que a condição de oferta tende a afetar o preço pago ao produtor local (CARVALHO et al., 2013). 
No primeiro período, $46,8 \%$ do movimento do preço do leite baiano são explicados pelo preço passado do próprio estado e 51,14\% são explicados pelo preço passado de Minas gerais. Já, o percentual 0,740\%, 0,518\%, 0,575\% e 0,222\% do movimento do preço pago ao produtor baiano, são explicados por choques, respectivamente, no Paraná, Rio Grande do Sul, Goiás e São Paulo. Os preços da Bahia possuem ao final de 40 meses, poder explicativo de $31,35 \%$ sobre si mesmo, $5,84 \%$ sobre os preços Goiano, $5,14 \%$ sobre os preços praticados no Rio Grande do Sul, 4,7\% dos preços de São Paulo, 4,65\% dos preços praticados no Paraná e 4,32\% sobre a Minas Gerais. Observa-se que a Bahia possui maior influência, ainda que pequena, que os estados de Paraná, Goiás e São Paulo. O estado do Paraná só ultrapassou no seu próprio estado e no Rio Grande do Sul, já Goiás e São Paulo ultrapassaram apenas nos seus próprios estados.

Diante dos resultados expostos, percebeu-se que o estado de Minas Gerais tem papel importante na formação de preços dos demais estados, destacando-se como o maior formador do preço do leite pago ao produtor, isto devido, principalmente, à condição de maior produtor de leite do país, pelos elevados investimentos em tecnologia, pelo grande número de indústrias instaladas de transformação da matéria-prima leite, dentre outros aspectos que lhe conferem posição de destaque na cadeia produtiva de leite.

O teste de causalidade de Granger busca estabelecer as relações de causalidade entre as variáveis, com o objetivo de compreender, se variações nos preços dos estados Minas Gerais, Paraná, Rio Grande do Sul, Goiás e São Paulo afetarão os preços pagos ao produtor de leite baiano, ou seja, saber se os estados causam no sentido de Granger variações percentuais nos preços praticados na Bahia.

A Tabela 3 apresenta os resultados para o referido teste. Desta forma, rejeita-se a hipótese nula de não haver causalidade de Granger. Por isso os valores passados dos preços recebidos pelos produtores de Minas Gerais, Paraná, Rio Grande do Sul, Goiás, e São Paulo, além, dos valores passados do próprio estado da Bahia, explicam o preço presente pago ao produtor baiano.

Tabela 3: Teste de causalidade de Granger das variáveis MG, RG, PR, GO, SP para BA janeiro de 2000 a junho 2015

\begin{tabular}{l|l|l|r}
\hline Hipótese nula & Observações & F-Statistic & Significância \\
\hline MG não causa Granger BA & 185 & 7.7556 & 0.0059374 \\
PR não causa Granger BA & 185 & 0.0102 & 0.9197821 \\
RG não causa Granger BA & 185 & 0.8205 & 0.3662750 \\
GO não causa Granger BA & 185 & 0.0215 & 0.8836122 \\
SP não causa Granger BA & 185 & 0.2077 & 0.6491304 \\
BA não causa Granger BA & 185 & 0.0007 & 0.9791255 \\
\hline
\end{tabular}

Fonte: : Elaborado pelo autor (2015), com base nos dados da pesquisa 
Os dados nos permitem rejeitar com o grau de confiança de 5\% a hipótese nula de que MG não causa no sentido de Granger, variações percentuais no preço da BA. Por outro lado, os dados não nos possibilitam a rejeição da hipótese nula de que variações percentuais no preço de PR, RS, GO e SP não causam no sentido de Granger variações nos preços da BA. Isto significa que os valores passados dos preços recebidos pelos produtores mineiros ajudam a explicar melhor os preços presentes do leite na Bahia.

Confirmou-se pelo teste de causalidade de Granger que o estado de Minas Gerais causa variações percentuais nos preços praticados na Bahia. Em suma, conclui-se que a análise conduzida neste artigo não permitiu rejeitar a hipótese determinada inicialmente, uma vez que, a partir das estimativas realizadas certificou-se empiricamente a importância do estado de Minas Gerais sobre a determinação dos preços do estado da Bahia e dos demais estados.

\section{Conclusões}

Diante dos resultados constatou-se que Minas Gerais tem papel importante na formação de preços de todos os estados. Devido, principalmente, à condição de maior produtor de leite do país. Isto também, pode ser explicado pelo elevado investimento em tecnologia e o grande número de indústrias instaladas de transformação da matéria-prima leite. Além disso o estado visa as políticas de desenvolvimento do setor, e as políticas de preço para o leite.

Para os estados do Sul (Rio Grande do Sul e Paraná), o maior formador de preço continua sendo Minas Gerais, porem esses estados são influenciados pelos seus próprios preços, de forma que os preços praticados em um estado dependem em grande parte do outro. Infere-se ser a menor distância entre esses dois estados a justificativa para essa transmissão. Os estados de São Paulo e Goiás possuem menor influência no mercado e dependem, em grande parte, dos preços praticados em Minas Gerais. Sofre influência também de seus próprios preços e ainda do estado do Rio Grande do Sul. Isso porque o leite produzido em São Paulo concorre com o leite importado do Rio Grande do Sul de modo que a condição de oferta tende a afetar o preço pago ao produtor local.

Com relação ao estado da Bahia, no qual se buscou uma análise mais detalhada, este sofre maior influência, em grande parte de Minas Gerais e, de seus próprios preços. No entanto, a Bahia apresentou maior influência nos preços que os demais estados, evidenciando um controle sobre os preços em seu mercado interno. Este fato pode ser explicado em 
decorrência da valorização das políticas de preço ao produto no Nordeste ocasionados pelos períodos de estiagem.

Pode-se observar a relação de integração entre os mercados produtores de leite, assim como a transmissão de preços intermercados. O fato de observar que os mercados dos estados selecionados são integrados permite concluir que eventuais políticas que afetam o processo de formação de preços em um estado vão também ter efeito nos preços de todos os demais estados com os quais ele esteja integrado, especialmente naqueles nos quais as relações são fortes. Este cenário aponta para a necessidade de políticas de preços para o leite focalizadas no estado de Minas Gerais.

\section{Referências}

CARVALHO, B. H. P. DE et al. Integração intra e inter-mercado: o caso dos preços do leite e derivados no Brasil. In: XLI Encontro Nacional de Economia. Anais...Foz do Iguaçu: ANPEC Associação Nacional dos Centros de Pósgraduação em Economia, 2013

CORRER, G. N. et al. O complexo Agroindustrial do leite: Estrutura e Transformações. In: 53 Congresso da Sociedade Brasileira de Economia, Administração e Sociologia Rural. Anais...João Pessoa: SOBER, 2015

CUNHA, D. A. DA et al. Integração e Transmissão de Preços no Mercado Internacional de Café Arábica. Revista de Economia e Sociologia Rural, v. 48, n. 4, p. 515-542, 2011.

DIAS, D. F. et al. Análise da transmissão de preço para o leite paranaense utilizando modelos de séries temporais. In: XLV Congresso Sociedade Brasileira de Economia, Administração e Sociologia Rural. Anais...Londrina: SOBER, jul. 2007

FACKLER, P. L.; GOODWIN, B. K. Spatial price analysis. Handbook of Agricultural Economics, p. 971-1024, 2001.

FAMINOW, M. D.; BENSON, B. L. Intergration of Spartial Markets.Pdf. American Journal of Agricultural Economics, p. 49-62, fev. 1990.

FERNANDES, R. A. S.; BRAGA, M. J.; LIMA, J. E. DE. Elasticidade de transmissão e formação espacial de preços de leite ao produtor nos maiores estados produtores. Revista de Economia e Administração, v. 9, n. 3, p. 368-385, 2010.

FONTES, A. A.; SILVA, M. L. DA; LIMA, J. E. DE. Integração espacial no mercado mineiro de carvão vegetal. Revista àrvore, v. 29, n. 6, p. 937-946, 2005.

GOODWIN, B.; HARPER, D. C. Price transmission, Threshold behavior, and asymmetric adjustment in the U.S. pork sector. Journal of Agricultural and Applied Economics, p. 543-553, 2000.

GRANGER, C. W. J. Investigating Causal Relations by Econometric Models and Cross-spectral Methods. Econometrica, v. 37, n. 3, p. 424-438, 1969.

GUJARATI, D. N. Econometria Básica. Rio de Janeiro: Elsevier, 2006.

IBGE - INSTITUTO BRASILEIRO DE GEOGRAFIA E ESTATÍSTICA. Pesquisa Pecuária Municipal 2014. Disponível em: <http://www.sidra.ibge.gov.br/bda/pesquisas/ppm/default.asp>. Acesso em: 20 abr. $2016 \mathrm{a}$.

IBGE - INSTITUTO BRASILEIRO DE GEOGRAFIA E ESTATÍSTICA. Produção da Pecuária Municipal 2014. Rio de Janeiro: (C) IBGE. 2015, 2014b. v. 42

JANK, M. S.; FARINA, E. M.; GALAN, V. B. O Agribusiness do leite no Brasil. $1^{\circ}$. ed. São Paulo: 
Milkbizz, 1999.

LOURES, A. R.; ALVIM, A. M.; LIMA, I. B. A causalidade de preços no mercado da bovinocultura leiteira no Rio Grande do Sul a partir de um Vetor Auto Regressivo ( VAR ). In: LIMA, Í. B. DE (Ed.). . Sustentabilidade econômica da agricultura familiar. 1. ed. São João Del Rei: UFSJ, 2013. p. 199-223.

MARTINS, P. DO C. et al. Cenários para o leite no Brasil em 2020. $1^{\text {a }}$. ed. Juiz de Fora: Embrapa, 2007.

NOGUEIRA, F. T. P. Integração espacial e efetividade do "hedge" no mercado brasileiro de café arábica. Viçosa: Universidade Federal de Viçosa - UFV, 2001.

ROSADO, P. L. Integração Espacial entre os mercados brasileiros de suíno. Viçosa: Universidade Federal de Viçosa - UFV, 2006.

SAMPAIO, C. A. R. Bahia busca autossuficiência na produção de leite. Disponível em: $<$ https://jornaloexpresso.wordpress.com/2014/09/26/bahia-busca-autossuficiencia-na-producao-deleite/>. Acesso em: 12 jul. 2015.

SECRETÁRIA DE ESTADO DA AGRICULTURA E DO ABASTECIMENTO - SEAB. Análise da conjuntura agropecuáriaDepartamento de Economia Rural - DERAL, 2014. Disponível em: <http://www.agricultura.pr.gov.br/arquivos/File/deral/Prognosticos/bovinocultura_lei>

USDA - UNITED STATES DEPARTMENT OF AGRICULTURE. Foreign Agricultural Service. Disponível em: <https://apps.fas.usda.gov/psdonline/>. Acesso em: 14 jul. 2016. 